\title{
Numerical Simulation Study on the Distribution Law of Deviatoric Stress of Floor under the Influence of Mining
}

\author{
Hongtao Liu $\mathbb{D}^{1},{ }^{1}$ Tianhong Huo, ${ }^{1}$ Yongen Li, ${ }^{1,2}$ Ming Luo, ${ }^{1}$ Guangdong Zhou, ${ }^{1}$ \\ and Zengji $\mathrm{He}^{1}$ \\ ${ }^{1}$ School of Energy and Mining Engineering, China University of Mining and Technology (Beijing), Beijing 100083, China \\ ${ }^{2}$ China Energy Guoyuan Electric Power Group, Beijing 100033, China \\ Correspondence should be addressed to Hongtao Liu; 108925@cumtb.edu.cn
}

Received 18 November 2020; Revised 13 January 2021; Accepted 19 January 2021; Published 9 February 2021

Academic Editor: Yanlin Zhao

Copyright (C) 2021 Hongtao Liu et al. This is an open access article distributed under the Creative Commons Attribution License, which permits unrestricted use, distribution, and reproduction in any medium, provided the original work is properly cited.

\begin{abstract}
The Zhaogu No. 2 coal mine is a single thick coal seam mining mine with high gas content. Due to the lack of protective layer mining conditions, we can only arrange the floor gas extraction roadway (FGER) to extract the gas from the overlying coal seam of the FGER to ensure safe production. However, improper placement of FGER will cause water inrush from the floor of FGER. Given above contradictions, this paper analyzes the stress-strain relationship of the fractured rock mass in the caving zone and the stress-recovery characteristics of the goaf from the perspective of the structural characteristics of the overlying strata above goaf. Based on this, a FLAC $^{3 \mathrm{D}}$ numerical model of equivalent delayed filling of caving rock mass was established by using the double-yield model filling method. The distribution of floor stress under the influence of mining is obtained after the model calculation, i.e., with the increase of the distance from the floor, the ratio of bidirectional stress to the peak value, and the stability value decrease, but the decrease amplitude becomes smaller and smaller. Therefore, floor roadway used for gas extraction should be located 10-15 m below the floor. Combined with the distribution of floor strata in 11060 working face, it is finally determined that FGER should be located $13 \mathrm{~m}$ below the floor. Such arrangement of FGER can not only ensure the effect of gas drainage but also prevent the occurrence of water inrush from floor.
\end{abstract}

\section{Introduction}

One of the effective methods to prevent coal and gas outburst is to excavate coal seam gas in advance by digging roadways. However, due to the difficulty of drilling holes in the topdraining roadway and the low extraction efficiency, the construction floor gas drainage roadway method was used to carry out regional gas control in the 11060 working face of Zhaogu No. 2 coal mine. At the same time, Zhaogu No. 2 coal mine has the problem of mining under confined water. If the gas drainage roadway is constructed on the coal seam floor, it will inevitably cause varying degrees of damage to the floor. If the construction location is improper, it may also cause the occurrence of water penetration accidents. In recent years, people have used various methods such as laboratory experiments, theoretical analysis, and numerical modeling to study fluid flow in fractured rock masses under different stresses and other conditions [1-5]. However, due to the extremely complex conditions of rocks and strata, such as water inrush from coal mine floor, in-depth research is still needed. Under the influence of overlying rock mining, the surrounding rock will have different degrees of stress deviation, namely, deviatoric stress, and the deviatoric stress at different positions will play a decisive role in the occurrence and development of plastic deformation of the surrounding rock $[6,7]$. The reasonable location selection of the floor gas extraction roadway (FGER) is of great significance for reducing or avoiding the risk of water inrush from the floor of Zhaogu No. 2 coal mine, which is also the significance of this paper.

Recent research results of domestic and foreign experts and scholars have shown that the reasonable location of the FGER is related to the overburden failure law in the upper coal face mining process, and many theories worth learning from are proposed, including the "in-situ cracking" theory and "zero damage" theory $[8,9]$, "key layer" theory $[10]$, "lower three belts" theory [11], "lower four belts" theory 
[12], "superior surface of water inrush" theory [13], "mutation theory" and "mutation model" [14], and "progressive ascending" theory [15]. At the same time, some scholars have summarized the relationship between floor roadways, coal pillars, and stope levels [16-19], and other scholars have studied the failure mechanism of floor roadways and roadways deformation characteristics of surrounding rock under the influence of mining [20-24]. However, the stress environment of the surrounding rock of the floor roadway is nonuniform. If the roadway is simplified as a plane strain problem, the surrounding rock of the roadway is affected by two-way stress. Most previous studies focused on the change of supporting pressure and ignored the two-way stress change impact on the roadway surrounding rock destruction. In recent years, through theoretical analysis and formula derivation, some scholars have obtained the boundary formula of the plastic zone of the roadway surrounding rock under the condition of the bidirectional unequal pressure deviatoric stress field [25], which opens a new way for the study of the plastic failure characteristics of roadway surrounding rock under the condition of nonuniform partial stress field [26-31].

The Zhaogu No. 2 coal mine has excavated a FGER to control the 11060 working face gas, but it may cause water inrush from the floor. Taking this contradiction as the starting point, the author uses the double-yield model method to simulate the caving zone of the filled goaf and numerically simulates the floor stress distribution law and the bidirectional stress ratio distribution law under the influence of mining stress in the FGER. The research results can provide reference for the reasonable layer selection of mine bottom extraction under the background of similar projects.

\section{Engineering Background}

As one of the main mines of Henan Coal Industry Chemical Group Coking Coal Company, Zhaogu No. 2 coal mine mainly mines 2-1 coal seam. The average coal thickness of 2-1 coal seam is $6.1 \mathrm{~m}$; its coal seam storage structure is simple and stable. According to the on-site investigation of Zhaogu No. 2 coal mine, the length of the working face is generally $160 \mathrm{~m}$, and the coal pillar size of the adjacent working face is $30 \mathrm{~m}$. The periodic pressing step of 11040 working face is $20 \mathrm{~m}$, and the initial pressing step is $37 \mathrm{~m}$. In order to control the gas in the deep area of the 11060 working face, the mine developed two parallel permanent main roads under the coal seam in the I panel; one is the west belt transportation road, and the other is the floor gas measure road. At the same time, in order to effectively eliminate the gas outburst of the coal seam in the working face, the 11060 working face floor gas drainage road was excavated. The FGER layout and the comprehensive column diagram of the coal floor rock strata are shown in Figure 1.

The Zhaogu No. 2 coal mine has a large water inflow. The $\mathrm{L}_{8}$ limestone aquifer is located under the 2-1 coal seam, and its thickness is generally $6.77-14.78 \mathrm{~m}$, and the distance from the 2-1 coal seam floor is $26-28.67 \mathrm{~m}$. The aquifer is welldeveloped with karst fissures, with relatively strong water richness, strong connectivity, and extremely heterogeneous, difficult to drain. The water pressure can reach $3.24-6.84 \mathrm{MPa}$, which is the main aquifer section that threatens the mining of the 2-1 coal seam. Overall, except for the permeable layer of $\mathrm{L}_{9}$ limestone, the remaining rock layers between the bottom surface of the 2-1 coal seam and the top surface of the $\mathrm{L}_{8}$ limestone are mainly mudstone and sandy mudstone. Because these two types of rocks have poorly developed voids and good water resistance, they are natural water barriers and the main water barriers that prevent floor water from filling the production space. The water barrier of each rock layer in the floor of Zhaogu No. 2 coal mine is shown in Figure 2.

\section{Goaf Compaction Mechanism and Determination of the Simulation Scheme}

3.1. Goaf Compaction Mechanism. Before the working face is mined, the roadway is basically only affected by in situ stress field. However, the mining of the working face caused largescale destruction of the in situ stress balance, and the in situ stress began to redistribute to form a new mine-induced stress field. Academician M. G. Qian based on a large number of onsite mine pressure monitoring data, the mechanical model of " voussoir beam" and "key strata theory" of rock structure are proposed; in the vertical direction, the overlying rock layer is divided into caving zone, fracture zone, and curve subsidence zone; in the horizontal direction, it forms the coal wall support zone, roof bed separation zone, and goaf compaction zone [32]. In the "three-zone" structure formed by the overlying rock structure of the stope, the height of the caving zone and the fracture zone will directly affect the movement of the overlying rock in the stope and the force of the floor in the goaf; the stress distribution characteristics of the stope floor will directly affect the surrounding rock stress environment of the FGER that excavated under the floor; thus, the height of the caving zone and the fracture zone in the overlying rock structure of the stope will be of great significance to the FGER engineering of Zhaogu No. 2 coal mine.

Academician M. G. Qian and other scholars combined with many domestic field experiences summed up a set of empirical estimation methods for the height of the caving zone and fracture zone [32]. Due to the complexity and variability of site conditions, it is difficult to ensure accuracy when using the estimation method to determine the height of the caving zone and the fracture zone. Yavuz [33] proposed the formula (1) that describes the relationship between the height of the caving zone and the mining height and the breaking expansion coefficient, and scholars Bai et al. [34] obtained the regression formula (2) of the height of the caving zone and the fracture zone after summarizing and statistically analyzing the measured data of a large number of mines in China and the United States.

$$
\begin{gathered}
H_{c}=\frac{h}{b-1}, \\
\left\{\begin{array}{l}
H_{c}=\frac{100 h}{c_{1} h+c_{2}}, \\
H_{f}=\frac{100 h}{c_{3} h+c_{4}} .
\end{array}\right.
\end{gathered}
$$




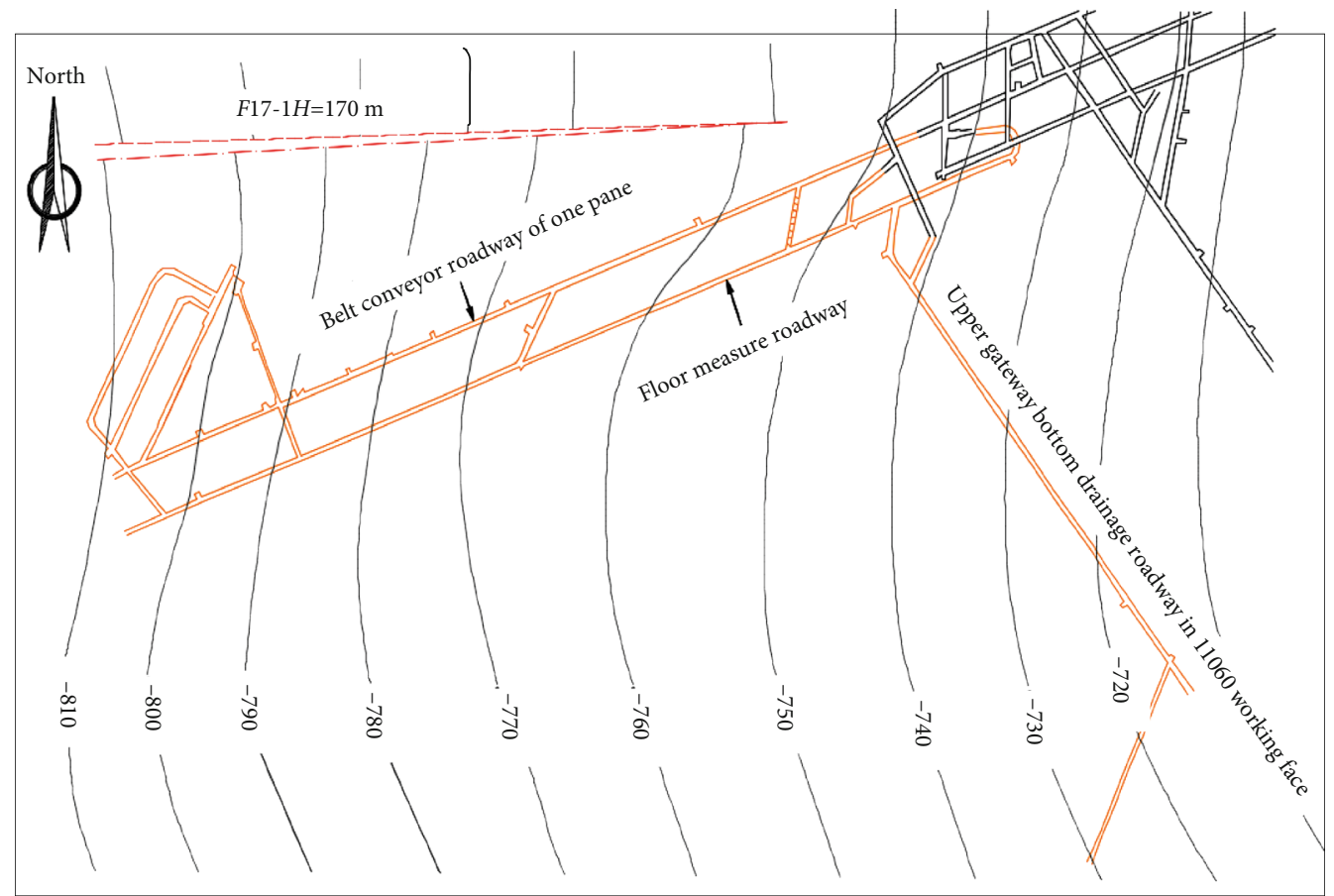

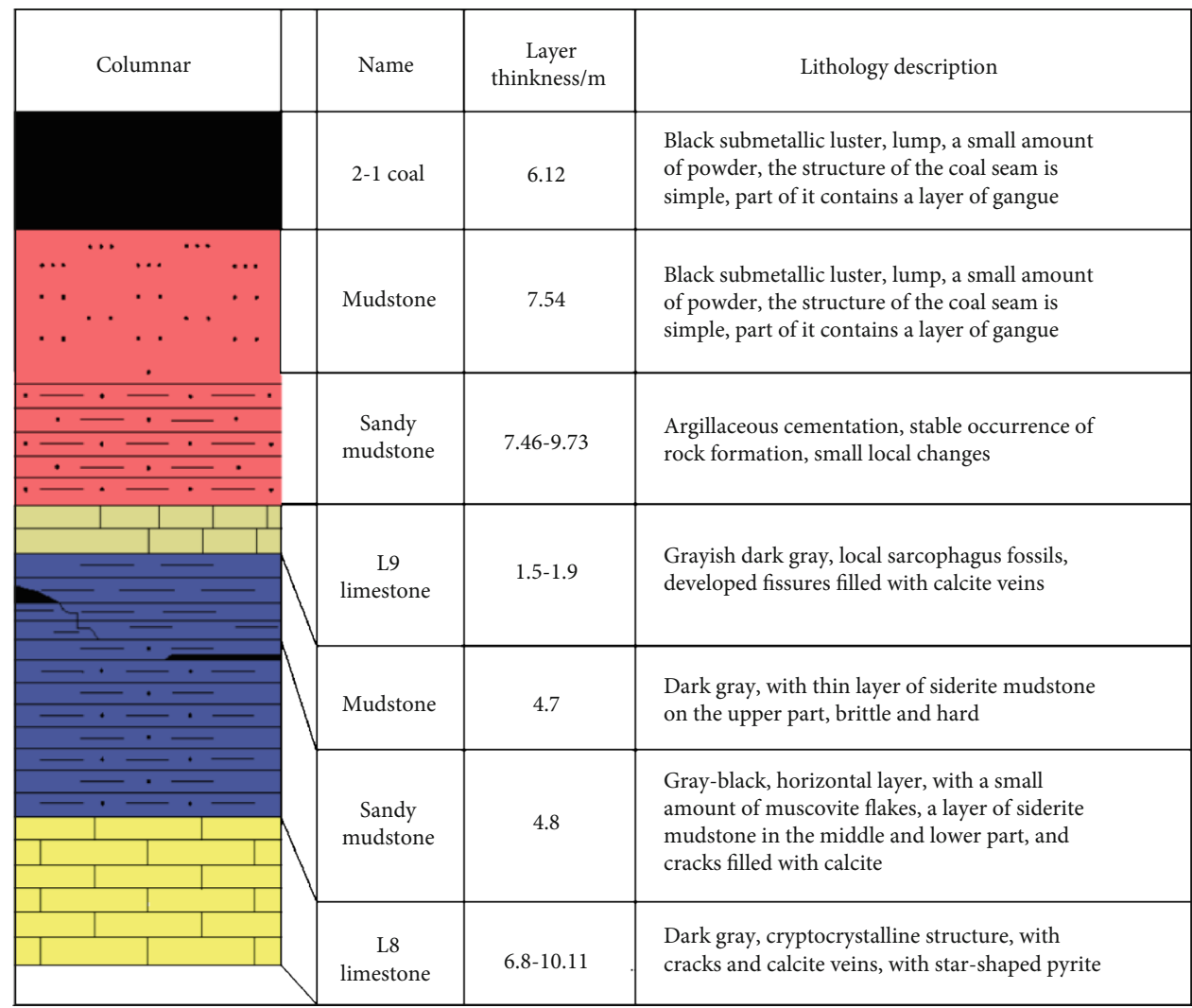

FIgURE 1: The FGER layout and comprehensive columnar diagram of coal floor rocks of the Zhaogu No. 2 coal mine.

In the formula, $H_{c}$ is the height of the caving zone, $H_{f}$ is the height of the fracture zone, $h$ is the mining height, $b$ is the breaking expansion coefficient, and $c_{1}, c_{2}, c_{3}$, and $c_{4}$ are the different strength coefficients of the roof strata [34]; the specific values are shown in Table 1.
The mining height $h$ of the 11060 working face of Zhaogu No. 2 coal mine is $6.1 \mathrm{~m}$, and the roof strata layer is medium-hard; combined with formula (2), it can be, respectively, calculated that the height of the caving zone and fracture zone is $12.8 \mathrm{~m}$ and $45.7 \mathrm{~m}$ during the mining 


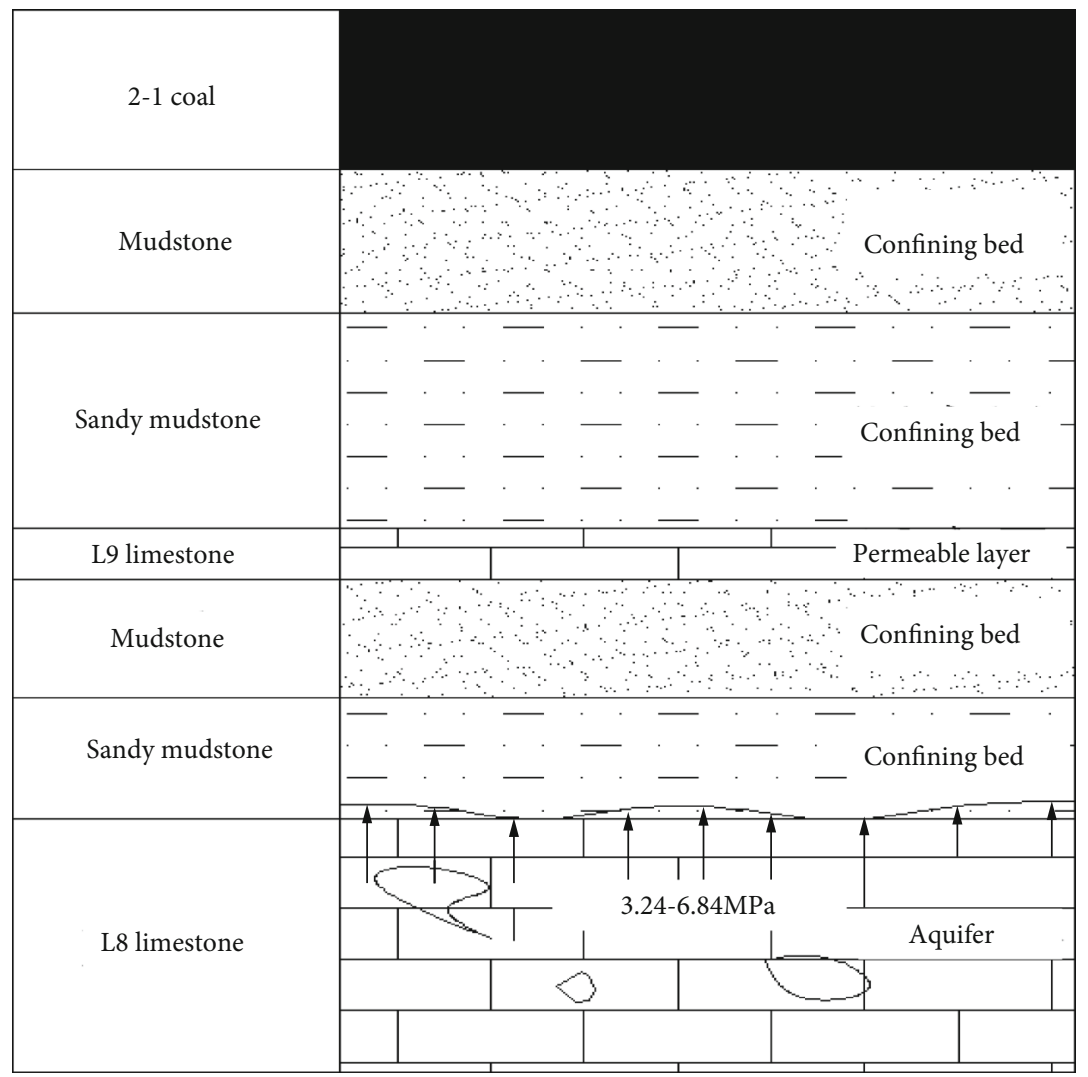

FIGURE 2: Schematic diagram of water barrier of floor rock in Zhaogu No. 2 coal mine.

TABLE 1: Rock strength coefficient of caving zone and fracture zone.

\begin{tabular}{lccccc}
\hline Lithology & $R_{c} / \mathrm{MPa}$ & $c_{1}$ & $c_{2}$ & $c_{3}$ & $c_{4}$ \\
\hline Weak & $<20$ & 6.2 & 32 & 3.1 & 5 \\
Medium-hard & $20 \sim 40$ & 4.7 & 19 & 1.6 & 3.6 \\
Hard & $<20$ & 2.1 & 16 & 1.2 & 2 \\
\hline
\end{tabular}

of the working face of No. 1 coal seam in Zhaogu No. 2 coal mine.

During the mining process of the working face, the rock layer in the immediate roof above the stope will fall freely as the working face advances, because the broken rock block collapses irregularly; the initial looseness coefficient can generally reach $1.3 \sim 1.5$; in the late stage, it is recompacted under the action of the overlying rock structure above; thus, the floor stress can be transmitted to the floor of the goaf so that the floor stress of goaf can be restored. Salamon [35] obtained the stressstrain relationship of the broken rock mass in the goaf through the compression experiment, as shown in formula (3); he obtained the stress-strain relationship of the rock mass in the caving zone during the compaction process by inversion:

$$
\sigma=\frac{E_{0} \varepsilon}{1-\varepsilon / \varepsilon_{\max }} .
$$

In the formula, $\sigma$ is the vertical stress of the broken rock mass in the caving zone, $E_{0}$ is the initial tangent modulus of the rock mass, $\varepsilon$ is the strain of the collapsed broken rock mass under the action of vertical stress, and $\varepsilon_{\max }$ is the maximum strain after the collapsed broken rock mass breaks and expands.

Yavuz [33] summarized and studied a large number of rock uniaxial compression tests and obtained the formula (4) between the initial tangent modulus $E_{0}$ of the rock mass and the breaking expansion coefficient $b$ of the rock mass and the uniaxial compressive strength $R_{c}$ through regression analysis, and the relationship between the maximum strain $\varepsilon_{\max }$ of broken rock mass after breaking expansion and the breaking expansion coefficient $b$ is shown in formula (5).

$$
\begin{aligned}
E_{0} & =\frac{10.39 R_{c}^{1.042}}{b^{7.7}}, \\
\varepsilon_{\max } & =\frac{b-1}{b} .
\end{aligned}
$$

Combining the above formulas, the relationship between the breaking expansion coefficient $b$ and the strength parameters of the rock mass, the mining height $h$ of the working face, and the stress-strain relationship of the broken rock mass in the caving zone during the force compaction process can be obtained as the formulas (6) and (7) are shown.

$$
\begin{aligned}
b & =1+\frac{c_{1} h+c_{2}}{100}, \\
\sigma & =\frac{10.39 R_{c}{ }^{1.042}}{b^{7.7}} \cdot \frac{\varepsilon}{1-b \varepsilon /(b-1)} .
\end{aligned}
$$




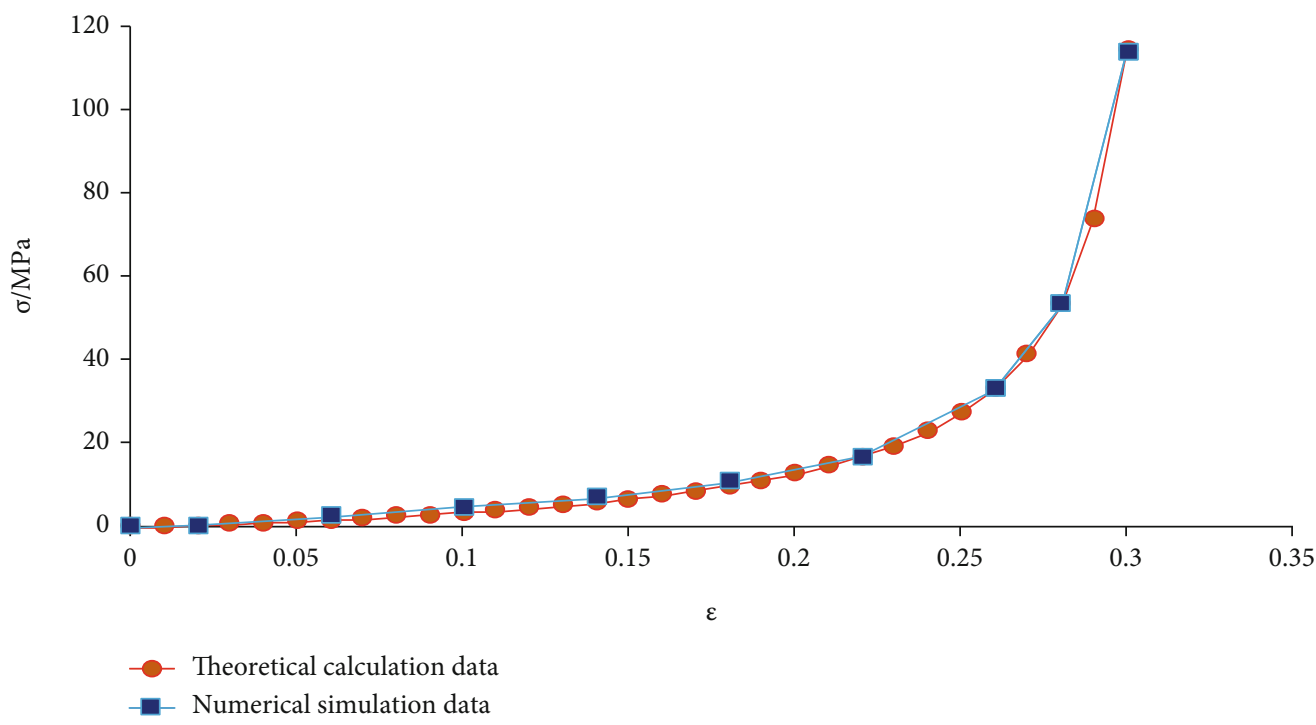

FIGURE 3: Stress-strain relationship of rock mass in caving zone and mechanical inversion of double-yield model.

TABLE 2: Mechanical parameters of rock mass filled in caving zone.

\begin{tabular}{cccccc}
\hline$K / \mathrm{GPa}$ & $G / \mathrm{GPa}$ & $\rho / \mathrm{kg}^{-3}{ }^{-3}$ & $\varphi /\left(^{\circ}\right)$ & $c / \mathrm{MPa}$ & $R_{m} / \mathrm{MPa}$ \\
\hline 19.9 & 1 & 2500 & 30 & 0.001 & 0 \\
\hline
\end{tabular}

It can be seen that the relationship of stress-strain of the broken rock mass in the caving zone during the force compaction process is determined by the uniaxial compressive strength $R_{\mathrm{c}}$ and the breaking expansion coefficient $b$; the breaking expansion coefficient $b$ is closely related to the mining height of the working face and the overlying rock lithology of the stope. Formula (7) shows the mechanical evolution characteristics of the broken rock mass in the caving zone from a loose state to a compacted state under the pressure of the overburden; the petrophysical and mechanical parameters of the No. 2 coal seam in Zhaogu No. 2 coal mine are taken into formulas (5) and (6), and the maximum strain $\varepsilon_{\max }$ of the broken rock mass in the goaf behind the working face is 0.32 , and the breaking expansion coefficient $b$ is 1.47. Combining formulas (3) and (4) can obtain the stress-strain relationship of the broken rock mass in the caving zone during the force compaction process, as shown in Figure 3. It can be seen that the stress-strain relationship of the broken rock mass in the goaf from loosening to compacting under the action of the overburden pressure shows an exponential growth trend; it shows that in the initial stage of compaction of broken rock mass, the displacement of the overlying rock above has a small effect on the collapsed broken rock mass; with the continuous structural deformation of the roof rock, the stress on the broken rock mass below also increases rapidly; until the overlying rock structure above compacts the broken rock mass below, the stress balance between the two is reached; however, due to the characteristics of the rock mass, the collapsed broken rock mass cannot be compacted to the initial complete volume, so the broken rock mass will always retain residual breaking expansion.
3.2. Numerical Simulation Method of Stress Recovery in Goaf. By establishing the relationship between the plastic zone of the roadway surrounding rock and the bidirectional stress ratio under the influence of water pressure, the FLAC ${ }^{3 \mathrm{D}}$ software which is more accurate and effective for the calculation of stress and plastic failure was selected; however, FLAC $^{3 \mathrm{D}}$ is a continuous medium software, and it cannot simulate the impact of the immediate roof collapse on the floor stress of the goaf; the commonly used methods for simulating the stress recovery of the goaf are the filling method and the setting large deformation interface method; the former is relatively simple and straightforward, while the latter is complicated to set up, and when using the latter, in order to make the roof and floor contact to achieve the effect of stress transfer, smaller lithological parameters and the interface with too high stiffness are often required, so the filling method is used to reflect the stress recovery of the goaf.

When using the filling method to simulate stress recovery, the filling rock mass can adopt an elastic model, elasticplastic model, double-yield model, etc. Because the elastic model is too ideally filled, it is not considered. The stressstrain relationship has been determined when the elasticplastic model is used, and sometimes, it does not reflect the stress-strain relationship under specific engineering conditions; in recent years, many scholars at home and abroad have used the double-yield model to fill the caving zone in the goaf; it has been accepted and used by many scholars and scientific researchers because of its customizable stressstrain relationship of the filling rock mass.

Combined with the roof lithology of Zhaogu No. 2 coal mine, by using the FLAC3D software, uniaxial compression simulation experiments were performed on the broken rock mass in the caving zone. Trial and error inversion method is used to obtain rock mass mechanical parameters with a high degree of fit to the stress-strain relationship of the theoretical calculation formula; the numerical simulation inversion results are shown in Figure 3, and the mechanical 


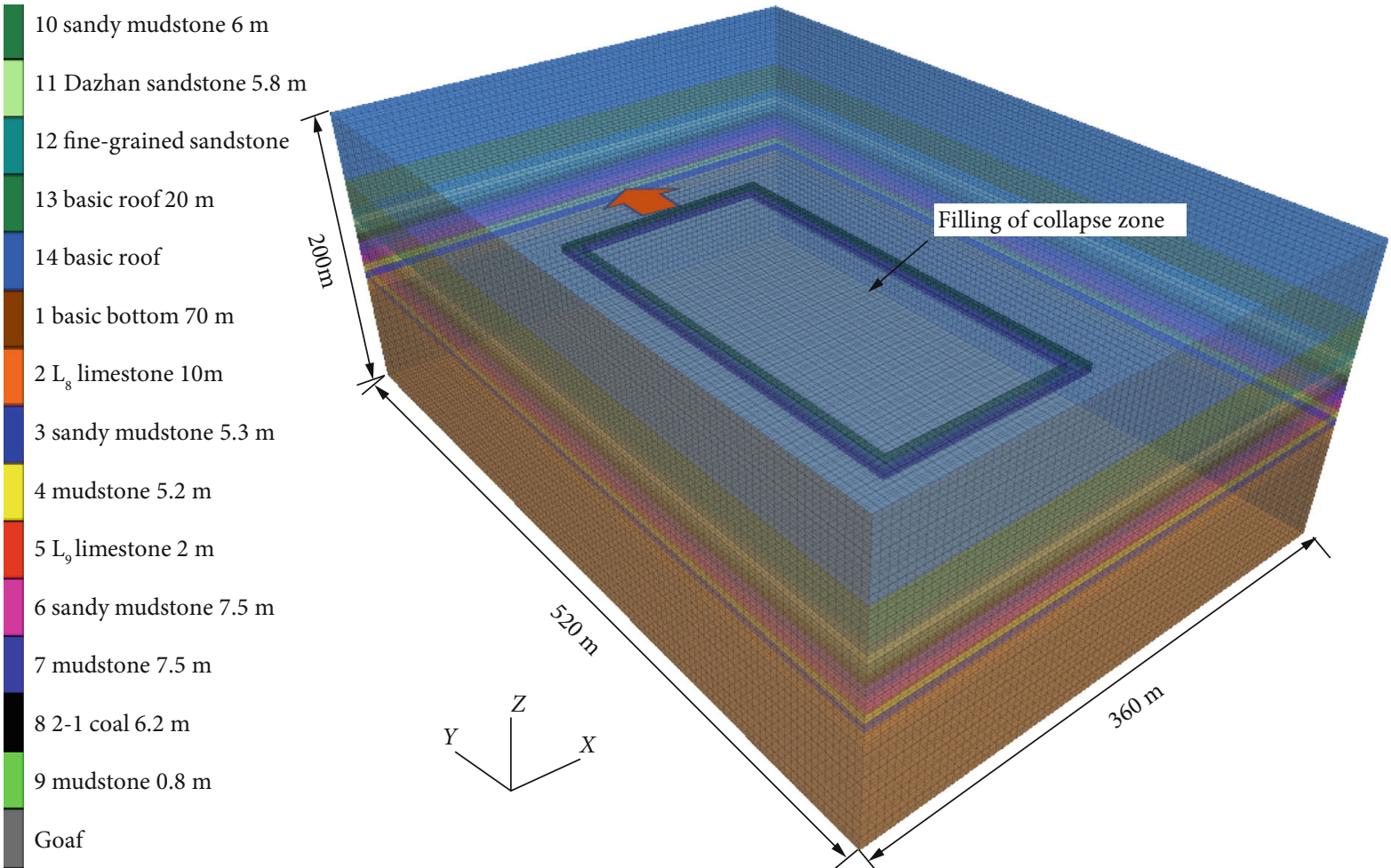

FIGURE 4: Numerical model of stress distribution of working face floor.

TABLE 3: Rock mechanical parameters selected by the model.

\begin{tabular}{|c|c|c|c|c|c|c|c|c|}
\hline Name of rock & Rock thickness & Cumulative buried depth & $\rho / \mathrm{kg}^{\prime} \mathrm{m}^{-3}$ & $K / \mathrm{GPa}$ & $G / \mathrm{GPa}$ & $\left.\varphi / /^{\circ}\right)$ & $c / \mathrm{MPa}$ & $R_{m} / \mathrm{MPa}$ \\
\hline 15 the FGER & \multirow{2}{*}{ - } & \multirow{2}{*}{700} & 2500 & 10.44 & 4.54 & 28 & 5.36 & 2.60 \\
\hline 14 basic roof & & & 2500 & 7.60 & 6.50 & 35 & 13 & 4.5 \\
\hline 13 basic roof & $20 \mathrm{~m}$ & 720 & 2500 & 7.60 & 6.50 & 35 & 13 & 4.5 \\
\hline 12 fine-grained sandstone & $7 \mathrm{~m}$ & 727 & 2500 & 7.60 & 6.50 & 35 & 13 & 4.5 \\
\hline 11 Dazhan sandstone & $5.8 \mathrm{~m}$ & 732.8 & 2700 & 10.20 & 9.00 & 38 & 16 & 7.5 \\
\hline 10 sandy mudstone & $6 \mathrm{~m}$ & 738.8 & 2500 & 10.44 & 4.54 & 28 & 5.36 & 2.60 \\
\hline 9 mudstone & $0.8 \mathrm{~m}$ & 739.6 & 2200 & 8.82 & 5.04 & 30 & 5.24 & 1.48 \\
\hline $82-1$ coal & $6.2 \mathrm{~m}$ & 745.8 & 1500 & 5.4 & 4.8 & 25 & 2.8 & 1.5 \\
\hline 7 mudstone & $7.5 \mathrm{~m}$ & 753.3 & 2200 & 8.82 & 5.04 & 30 & 3.24 & 1.48 \\
\hline 6 sandy mudstone & $7.5 \mathrm{~m}$ & 760.8 & 2500 & 10.44 & 4.54 & 28 & 5.36 & 2.60 \\
\hline $5 \mathrm{~L}_{9}$ limestone & $2 \mathrm{~m}$ & 762.8 & 2700 & 12.6 & 8.3 & 40 & 10 & 8.71 \\
\hline 4 mudstone & $5.2 \mathrm{~m}$ & 867.0 & 2200 & 8.82 & 5.04 & 30 & 3.24 & 1.48 \\
\hline 3 sandy mudstone & $5.3 \mathrm{~m}$ & 773.3 & 2500 & 10.44 & 4.54 & 28 & 5.36 & 2.60 \\
\hline $2 \mathrm{~L}_{8}$ limestone & $10 \mathrm{~m}$ & 783.3 & 2700 & 12.6 & 8.3 & 40 & 10 & 8.71 \\
\hline 1 basic bottom & $70 \mathrm{~m}$ & 853.3 & 2700 & 12.6 & 8.3 & 40 & 10 & 8.71 \\
\hline Goaf & - & - & 2500 & 19.9 & 1 & 30 & 0.001 & 0 \\
\hline
\end{tabular}

parameters of the rock masses obtained in the caving zone are shown in Table 2.

By using the filling method to fill the goaf, it solves the shortcomings of nonrecovery of the goaf stress and relatively high coal pillar abutment pressure caused by the unfilled goaf in the traditional numerical simulation excavation calculation. At the same time, it can better reflect the stress-strain relationship of the broken rock mass in the goaf under the action of the overlying rock; it provides a guarantee for study- ing the stress environment and surrounding rock failure law of the FGER engineering in Zhaogu No. 2 coal mine when it is disturbed by the working face excavation.

3.3. Determination of the Simulation Scheme. As the FGER of 11060 working face in Zhaogu No. 2 coal mine is used for the upper working face's regional danger relief, the FGER is arranged before the working face; when mining at the working face, the FGER of 11060 working face will inevitably be 


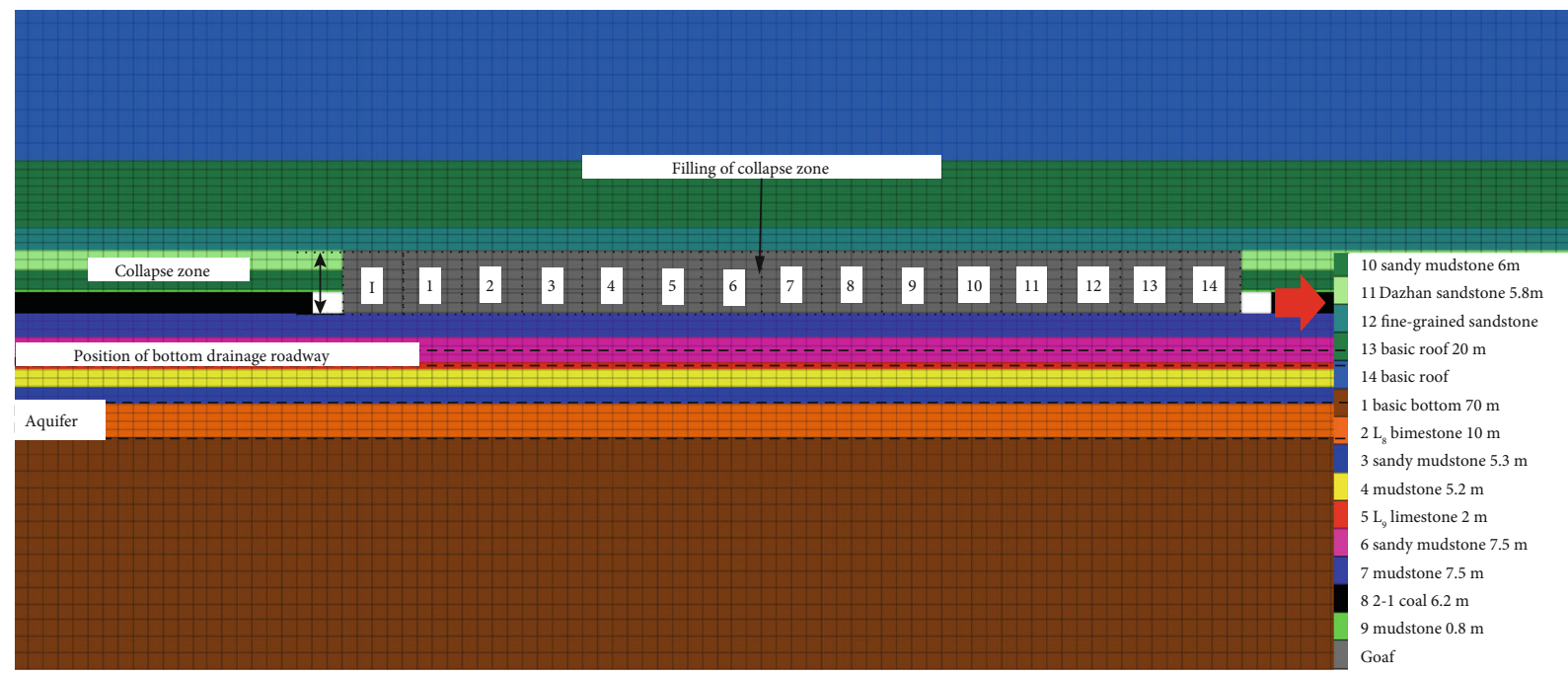

Figure 5: Layout of the stope excavation and filling.

affected by the mining stress of the upper working face; the stress environment of the surrounding rock of the FGER determines the damage range of the surrounding rock of the roadway. Therefore, in the mining process of the working face, the stress distribution law of the working face floor is extremely important, and it is the key to arranging FGER and the reasonable position of the working face.

Based on this, the numerical model shown in Figure 4 is established. The size of the model is $360 \mathrm{~m}, 520 \mathrm{~m}$, and $200 \mathrm{~m}$ in length, width, and height, respectively. By using the Mohr-Coulomb constitutive model, the horizontal displacement of the $x$ - and $y$-axis boundary and the vertical displacement of the lower boundary of the $z$-axis are, respectively, fixed. A compensation load of $17.5 \mathrm{MPa}$ was applied to the upper boundary of the model, initial stress $\mathrm{SZZ}=17.75 \mathrm{MPa}, \mathrm{SXX}=\mathrm{SYY}=23.075 \mathrm{MPa}$, and $4 \mathrm{MPa}$ pore water pressure was applied below the $\mathrm{L}_{8}$ limestone floor to simulate the water pressure of the aquifer.

In the model, the thickness of the roof and floor of the coal seam is modeled according to the actual geological thickness of the mine, and then, the basic top and the basic bottom are added above and below the roof to increase the thickness of the model and reduce the boundary effect. Combined with the calculation results of rock mechanical parameters, the model adopts the layer layout, and its rock mechanical parameters are shown in Table 3.

The working face was excavated along the $x$-axis to simulate the length of the working face. The excavation started from $100 \mathrm{~m}$ on the $y$-axis, and each excavation was $20 \mathrm{~m}$. A total of $320 \mathrm{~m}$ was excavated. According to the calculation results in Section 3.1, the mining time of the working face and the height of the collapse zone is $12.8 \mathrm{~m}$. The broken rock mass in the caving zone is equivalently simulated using a dual yield model. The filling scheme is determined as follows: the first two steps of excavation are not filled to simulate the stope environment before the initial pressure on the working face, and the lagging work face after the third step of excavation and the $10 \mathrm{~m}$ position is filled with filling bodies with length, width, and height of $140 \mathrm{~m}, 20 \mathrm{~m}$, and $12.8 \mathrm{~m}$, respec-

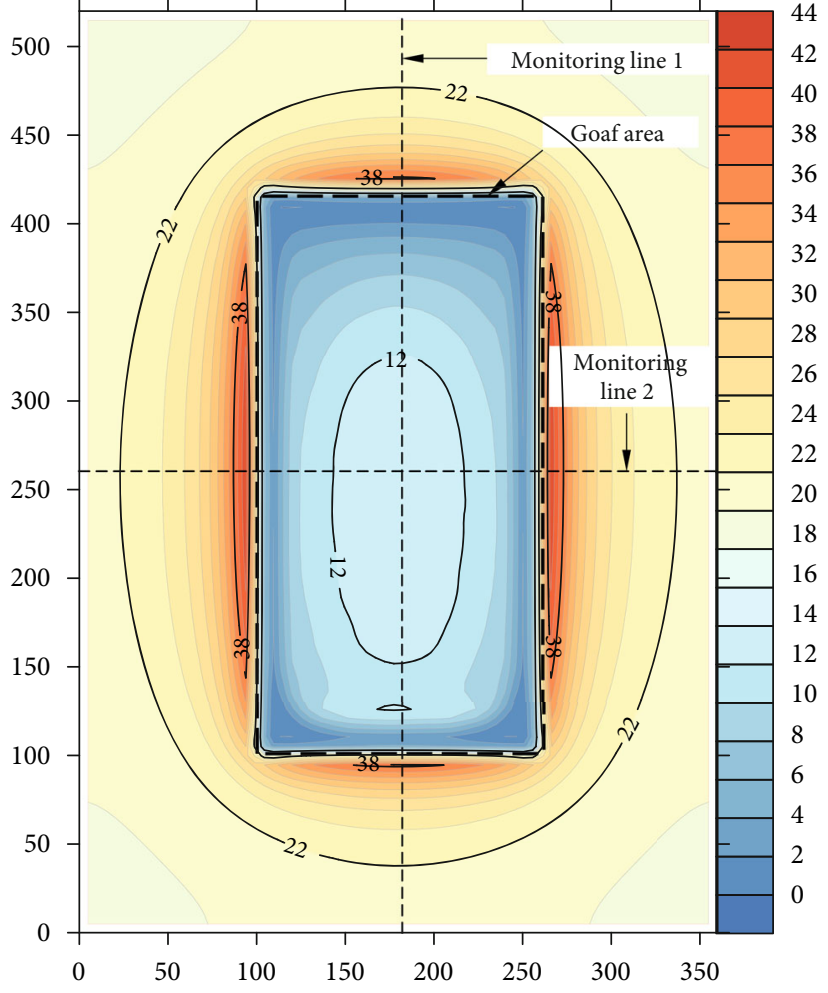

FIGURE 6: Distribution of abutment pressure of floor after mining.

tively. Then, the working face enters the periodic compression stage, and filling is carried out at a lag of $10 \mathrm{~m}$ after the excavation is $20 \mathrm{~m}$. A total of 15 excavations are carried out, and the goaf is filled 14 times. The specific filling arrangement is shown in Figure 5.

3.4. Selection of the Longitudinal Level of the FGER. Since the FGER is responsible for the function of predraining the gas in the upper coal seam and faces a strong water inrush hazard, the main considerations when the FGER is arranged in the longitudinal layer are as follows: according to regulations 


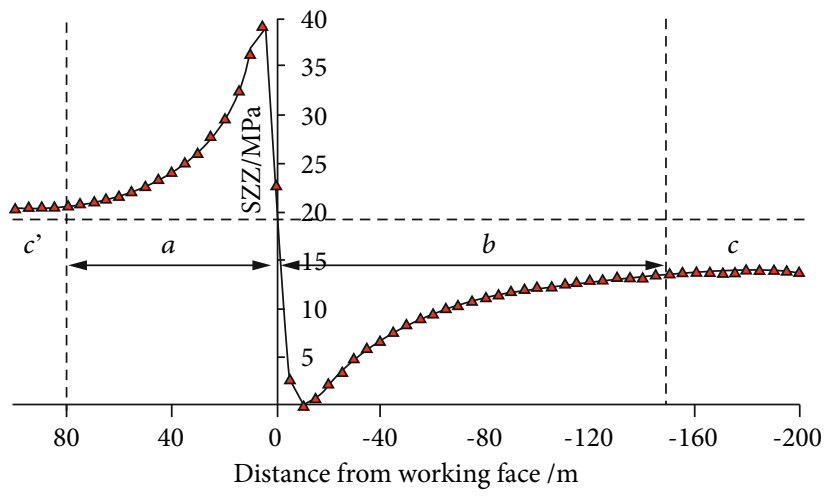

$\triangle-\mathrm{SZZ}$

(a) Vertical stress distribution in front and back of working face

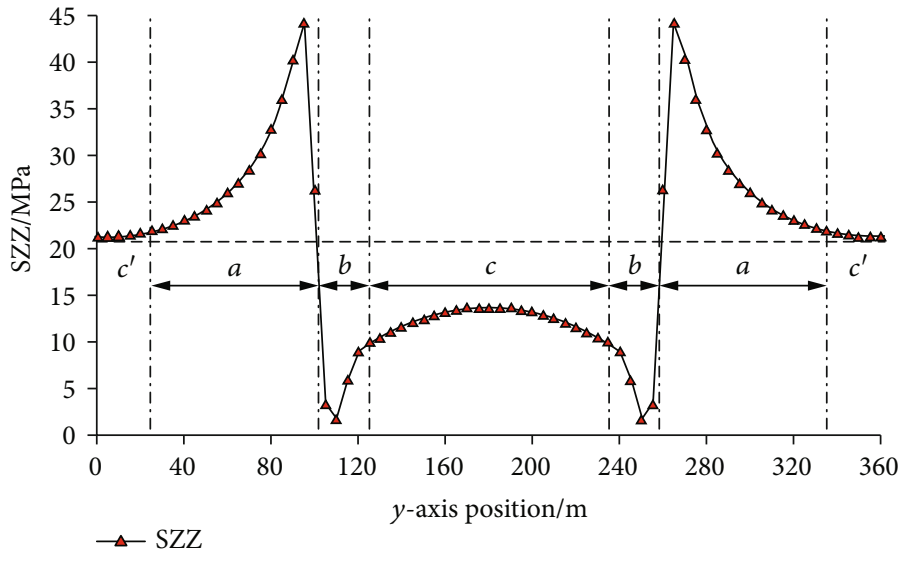

(b) Vertical stress distribution in the middle of goaf

Figure 7: Abutment pressure distribution at monitoring line.

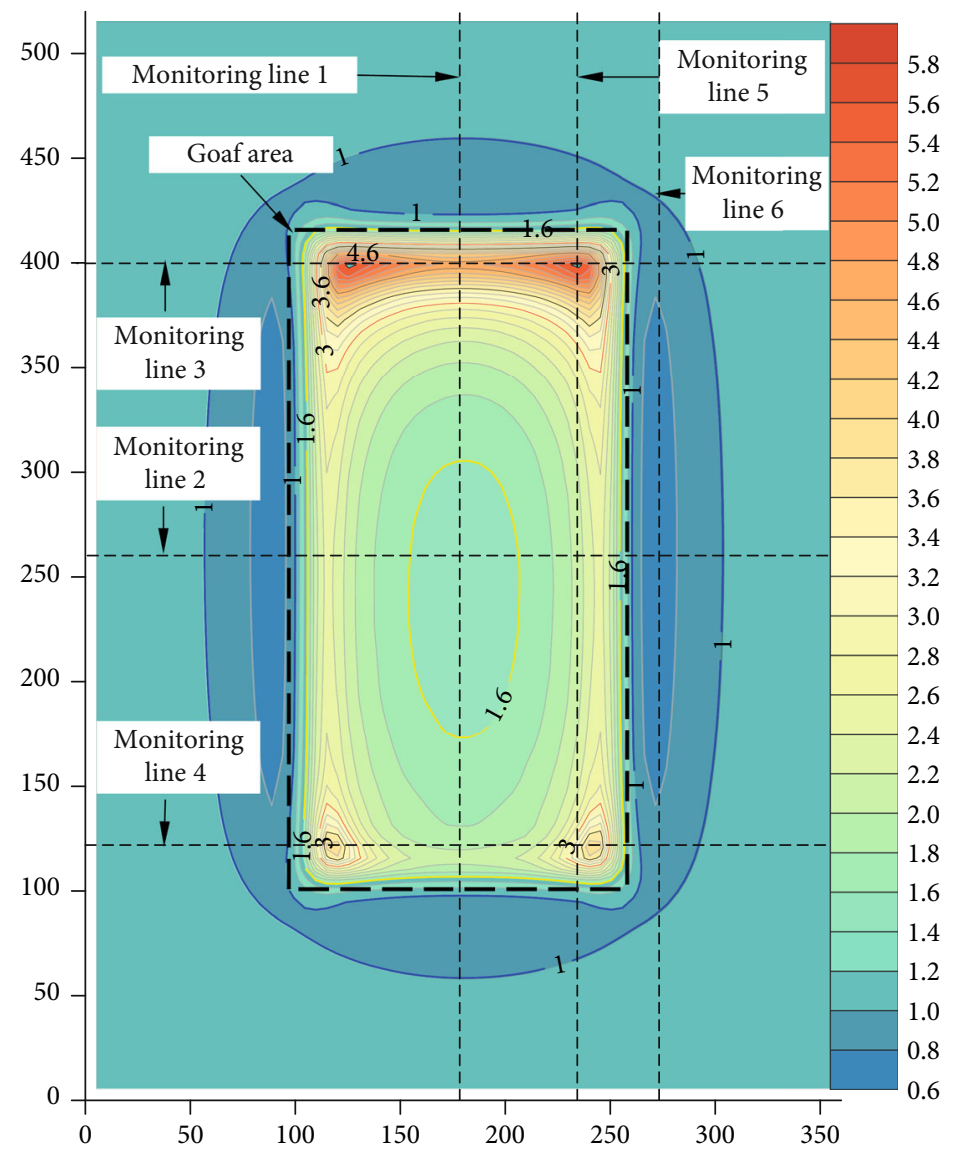

Figure 8: Bidirectional stress ratio distribution at $13 \mathrm{~m}$ below the floor.

on prevention of coal and gas outburst: when the minimum normal distance between all roadways outside the outburst coal seam and the outburst coal seam is less than $10 \mathrm{~m}$, they must be excavated while exploring to ensure that the minimum normal distance is not less than $5 \mathrm{~m}$. So it is necessary to ensure that the roof of the FGER is more than $10 \mathrm{~m}$ away from the coal seam floor; according to the geological drilling data, the FGER should be as far away as possible from the $\mathrm{L}_{8}$ limestone aquifer to reduce the risk of water inrush. At the same time, in order to meet the requirements for the use of extraction equipment, the tunnel section of the bottom extraction roadway adopts a straight wall semicircular arch, and the design section width and height are $5.0 \mathrm{~m}$ and $4.0 \mathrm{~m}$, respectively.

According to the columnar diagram of the floor rock, the distance from the coal floor to the $\mathrm{L}_{8}$ limestone is $26-28.67 \mathrm{~m}$; it can be seen that the optional layout range of the FGER in the longitudinal direction is very small, because the lithology 


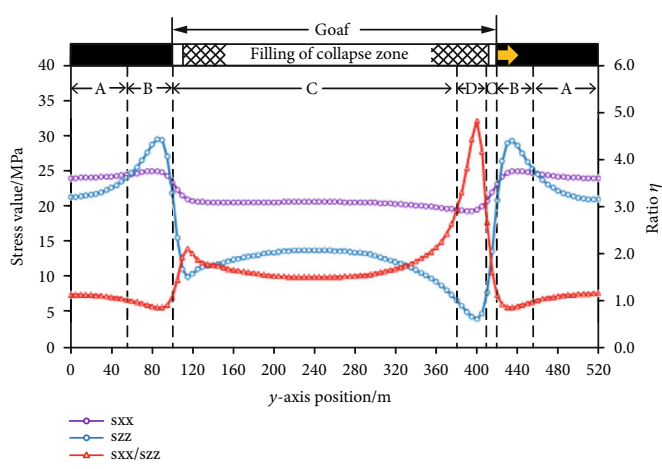

(a)

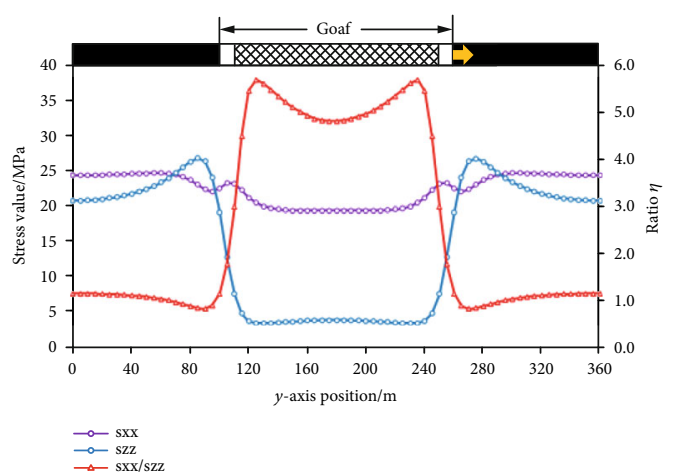

(c)

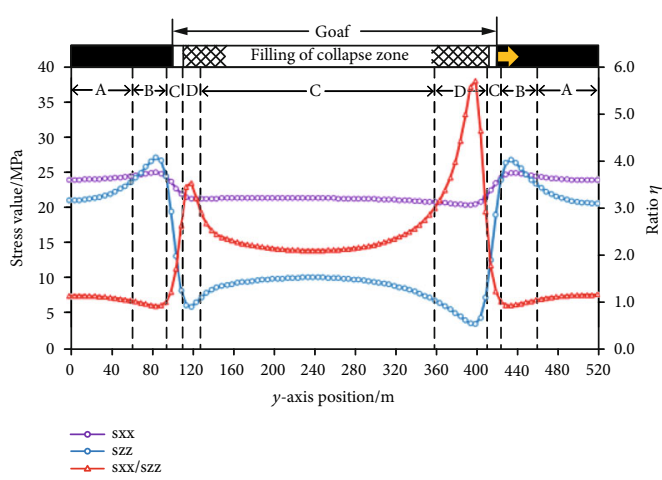

(e)

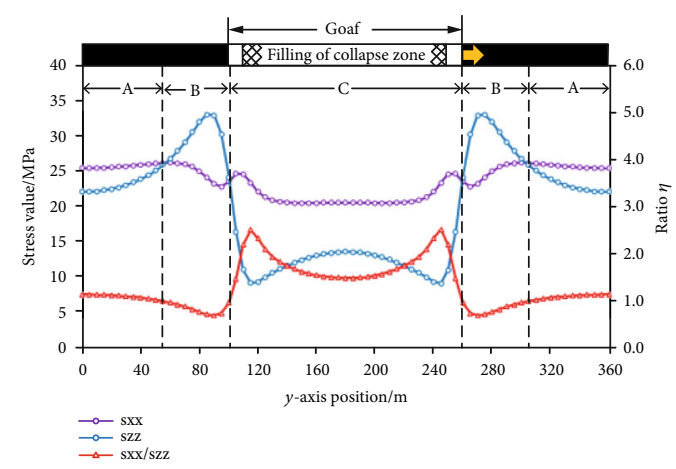

(b)

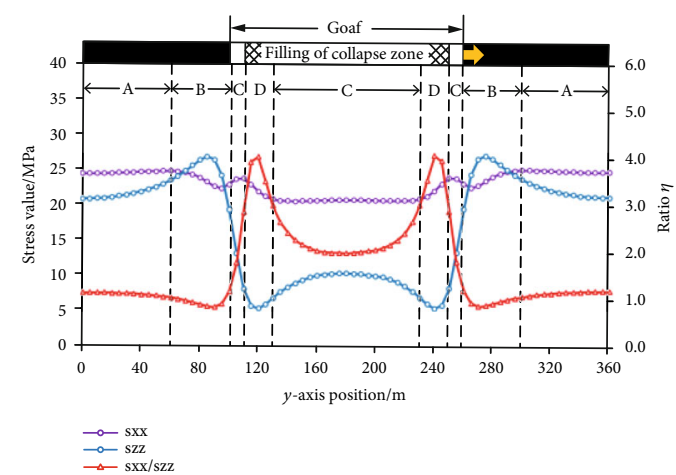

(d)

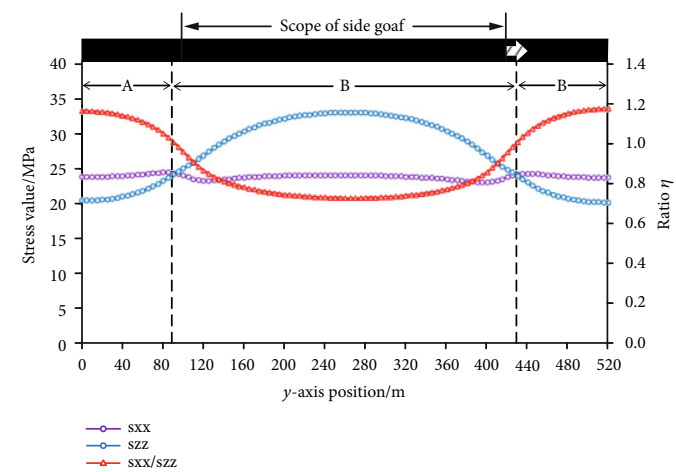

(f)

Figure 9: Stress value and its ratio at each monitoring line under the influence of mining: (a) monitoring line 1; (b) monitoring line 2; (c) monitoring line 3; (d) monitoring line 4; (e) monitoring line 5; (f) monitoring line 6.

of $\mathrm{L}_{9}$ limestone is hard and stable; if the roadway is excavated in the $\mathrm{L}_{9}$ limestone, it will undoubtedly increase the amount of excavation. If the roadway is excavated under the $\mathrm{L}_{9}$ limestone, on the one hand, the roadway will be too close to the aquifer; on the other hand, it is necessary to cross $\mathrm{L}_{9}$ limestone during the later construction of gas drainage drilling, which increases the drilling volume. Therefore, it is necessary to arrange the FGER above the $\mathrm{L}_{9}$ limestone in comprehensive consideration; if $\mathrm{L}_{9}$ is used as the floor of the FGER for excavation, its stronger lithology will increase the stability of the floor of the FGER and reduce the amount of floor maintenance work; its stable existence can be used as a sign of the FGER driving to ensure the longitudinal distance between the roadway and the coal seam, so the longitudinal layer layout of the FGER in Zhaogu No. 2 coal mine is to be driven along the floor in the sandy mudstone above the
$\mathrm{L}_{9}$ limestone; the center of the FGER is about $13 \mathrm{~m}$ away from the coal seam floor in the longitudinal layer direction.

\section{Bidirectional Stress Distribution Law of Working Face Floor under the Influence of Mining}

4.1. Distribution Law of Vertical Stress in Goaf. After the excavation of the working face is completed, the floor stress distribution is shown in Figure 6, and the vertical stress distribution of the normal direction in the middle of the working face and the tangential direction in the middle of goaf is shown in Figure 7.

It can be seen from Figure 6 that the vertical stress can be recovered in the goaf after filling with the double bending 
method, and the recovery effect is that the closer to the middle of the goaf, the better the recovery effect. At the same time, the vertical stress concentration appears in a certain area in the solid coal near goaf, and the closer the coal wall is, the greater the stress concentration is.

According to Figure 7(a), the vertical stress distribution in front and back of working face shows that the vertical stress increases within $80 \mathrm{~m}$ in front of the working face, and the vertical stress increases sharply within $30 \mathrm{~m}$ in front of the working face and reaches the maximum value of $39.2 \mathrm{MPa}$ at $5 \mathrm{~m}$ in front of the coal wall. Therefore, $0-80 \mathrm{~m}$ in front of the working face is the advanced abutment pressure area (A. pressurization area), and the abutment pressure concentration factor is 1.9. In the rear of the working face, the abutment pressure decreases sharply, and the vertical stress decreases to $0 \mathrm{MPa}$ at $10 \mathrm{~m}$ behind the working face. Due to the gradual compaction of the broken rock mass in the caving zone, the stress of the overlying strata is transferred to the coal seam floor so that the stress in the floor of goaf is gradually restored. With the distance from the working face getting farther and farther, the vertical stress gradually recovered from $0 \mathrm{MPa}$ at $10 \mathrm{~m}$ behind the working face to $13.8 \mathrm{MPa}$ at $150 \mathrm{~m}$ behind the working face. Therefore, the range of $0-150 \mathrm{~m}$ behind the working face is the stress reduction area (B. decompression area). The area where the vertical stress remains unchanged $150 \mathrm{~m}$ behind the working face is the constant stress area (C. pressure stabilizing area); $C^{\prime}$ is not affected by mining stress, and the vertical stress does not change. It is the original rock stress area and the pressure stabilizing area.

It can be seen from the lateral abutment pressure distribution in the middle of the goaf (as shown in Figure 7(b)), the vertical stress increases within $70 \mathrm{~m}$ behind the coal wall of the working face, and the abutment pressure increases sharply within $25 \mathrm{~m}$ behind the coal wall of the working face, and the maximum abutment pressure is $44.4 \mathrm{MPa}$, and the abutment pressure concentration factor is 2.1 , so the area within $70 \mathrm{~m}$ from the side of the working face is a pressurized area. The vertical stress decreases sharply to $1.8 \mathrm{MPa}$ at $10 \mathrm{~m}$ inside the coal wall in the middle of the goaf (as shown in Figure 7(a)). With the increase of the distance from the coal wall, the vertical stress rapidly recovered to $12.2 \mathrm{MPa}$ at $25 \mathrm{~m}$ away from the coal wall, and then, the recovery degree of the vertical stress slowed down to $13.8 \mathrm{MPa}$ in the middle of the goaf. Therefore, in the goaf 0-25 m away from the coal wall is the stress reduction area (B. decompression area); the other areas of the vertical stress increase degree are small; maintain stability is the stable area, $C$; $C^{\prime}$ is not affected by the mining stress; the vertical stress has not changed, is the original rock stress area, and also is the stable pressure area. Therefore, in the goaf $0-25 \mathrm{~m}$ away from the coal wall is the stress reduction area (B. decompression area), the other areas of the vertical stress increase degree are small; maintain stability is the stable area, $\mathrm{C} ; \mathrm{C}^{\prime}$ is not affected by the mining stress; the vertical stress has not changed, is the original rock stress area, and also is the stable pressure area.

The above analysis results show that under the influence of mining, the vertical stress distribution is concentrated near the coal wall, and the stress in the goaf presents the character-

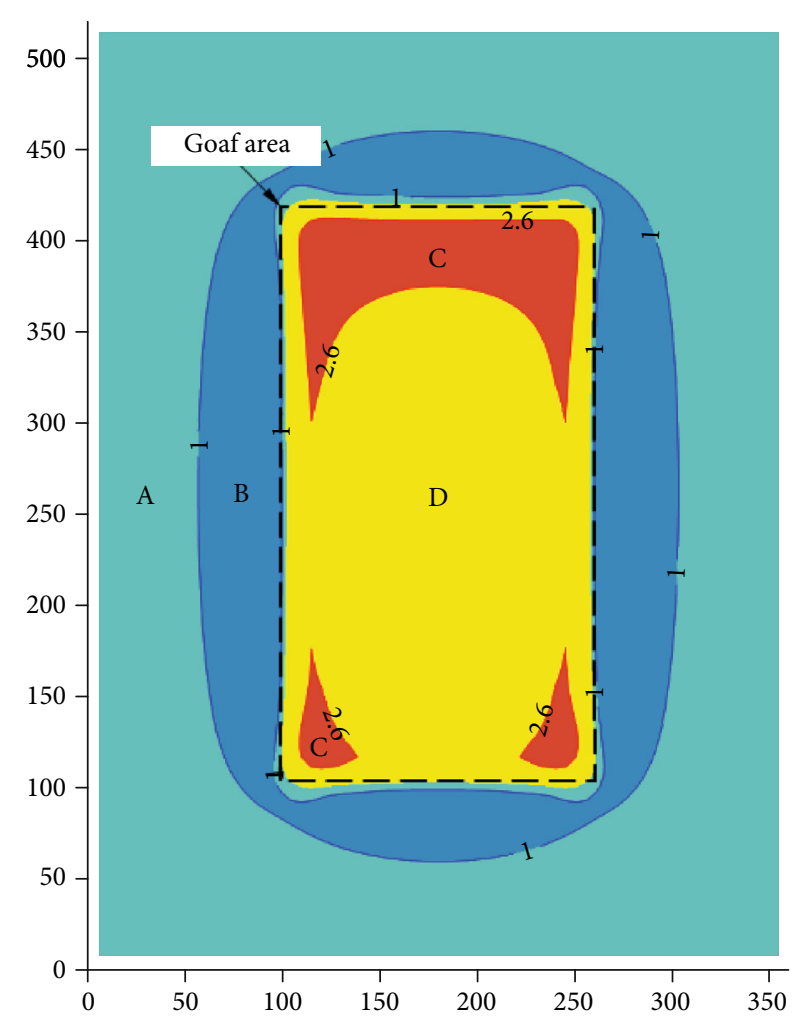

Figure 10: 2D diagram of bidirectional stress ratio zoning results.

istics of decreasing to gradually recovering. From the edge of the model to the middle of the goaf, according to the value of the vertical stress, it can be divided into the original rock stress area, the pressure increasing area, the pressure reducing area, and the pressure stabilizing area, which conforms to the distribution law of the floor supporting pressure after coal mining.

4.2. Distribution Law of Bidirectional Stress Ratio in Floor. The stress environment of roadway surrounding rock will directly affect its surrounding rock failure range, and the distribution characteristics of roadway surrounding rock failure range are also different under different bidirectional stress ratios. Therefore, when studying the surrounding rock failure range and water inrush risk of 11060 FGER under the influence of mining stress, we should not only consider the value of vertical stress but also consider the ratio of horizontal stress and bidirectional stress.

By extracting the stress data $13 \mathrm{~m}$ below the coal seam floor after the model excavation, the bidirectional stress ratio distribution of the coal seam floor in the central layer of the FGER can be obtained (as shown in Figure 8). In order to systematically analyze the stress distribution characteristics of each position under the influence of mining, six monitoring lines are arranged as shown in Figure 9. The monitoring line 1 is arranged in the normal direction in the middle of the working face, the monitoring line 2 is arranged in the tangential direction in the middle of the goaf, the monitoring line 3 is arranged in tangential direction $20 \mathrm{~m}$ behind the projection of working face, the monitoring line 4 is arranged in the tangential direction $20 \mathrm{~m}$ away from the starting cut in the 


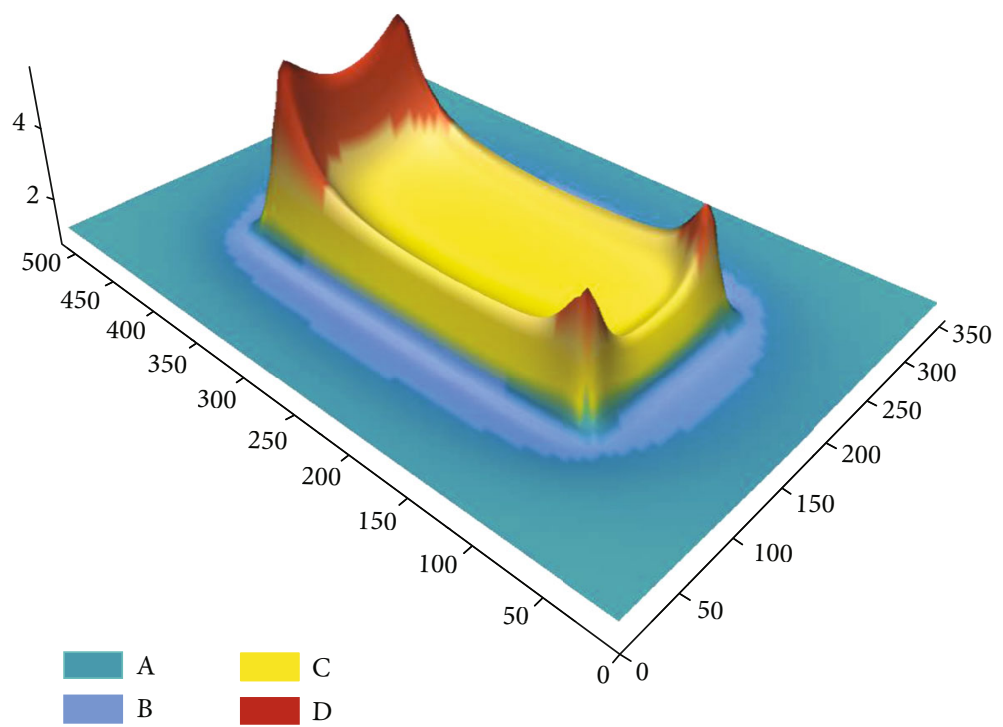

Figure 11: 3D diagram of bidirectional stress ratio zoning results.

projection of goaf, the monitoring line 5 is arranged in the normal direction $25 \mathrm{~m}$ away from the right end of the projection of the working face, and the monitoring line 6 is arranged in the longitudinal direction $15 \mathrm{~m}$ outside the projection of coal wall.

Under the influence of mining stress, there is a weak correlation between the change of vertical stress and horizontal stress, which makes the bidirectional stress ratio change sharply and regularly in the coal wall under the goaf. According to the analysis in Figures 8 and 9, under the influence of mining stress, the vertical stress changes significantly in the central layer of the FGER, while the variation range of horizontal stress is limited. According to the state of vertical stress, the floor can be divided into vertical stress pressurization state, vertical stress relief state, and original rock state. Because the distance between the center of the roadway and the floor of the coal seam is $13 \mathrm{~m}$, the increase of vertical stress is limited within the influence range of abutment pressure in the coal wall. However, in the vertical stress relief area below the goaf, the value of vertical stress will obviously decrease, and the vertical stress in the goaf will show obvious pressure relief at the edge of goaf due to the gradual compaction of rock mass in the upper caving zone, but the middle part gradually recovered.

According to the stress state and bidirectional stress ratio characteristics of each area, the area which is less affected by mining stress and $1<\eta<1.3$ can be defined as "original rock stress ratio area"; the area where the vertical stress is in pressurization state and $0.53<\eta<1$ is called "pressurization lowstress ratio area"; the area where the vertical stress is in the depressurized state and $1<\eta<3$ is called the "unloading low-stress ratio area"; the area where the vertical stress is in the state of pressure relief and $\eta>3$ is called "the area of high-stress ratio of pressure relief".

After the excavation of the model, the central layer of the FGER is partitioned according to the stress state and ratio (as shown in Figures 10 and 11). In Figure 10, area A is "original rock stress ratio area", area B is "pressurization low-stress

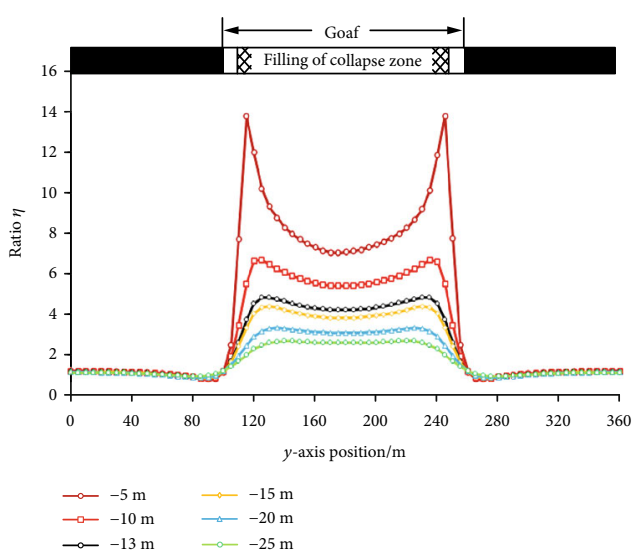

Figure 12: The ratio of two-way stress at different depths at the position of monitoring line 3 .

ratio area", area C is "unloading low-stress ratio area", and area D is "unloading high-stress ratio area." Area B is distributed in the projection range of coal wall outside the goaf and surrounded by area A. Under the goaf, the bidirectional stress ratio shows a concave shape which is higher at the edge of the goaf and lower in the middle of the goaf. From the longitudinal view, the bidirectional stress ratio presents a "high-low peak" shape with a peak at $20 \mathrm{~m}$ behind the working face and a low peak at $20 \mathrm{~m}$ in front of the starting cut. From a horizontal perspective, the peak points of the two-way stress ratio are symmetrically distributed at a position $20 \mathrm{~m}$ away from the coal wall, showing a steady M-shaped distribution characteristic between the two peaks, and the four peak points of the two-way stress ratio in the goaf are, respectively, distributed at four right angles of the goaf. The four peak points of the bidirectional stress ratio in the goaf are, respectively, distributed at four right angles of the goaf. According to the size of the stress ratio, the "pressure relief high-stress ratio zone" is mainly distributed in the range of the goaf from $10 \mathrm{~m}$ to $50 \mathrm{~m}$ behind the working face, more than $10 \mathrm{~m}$ from 


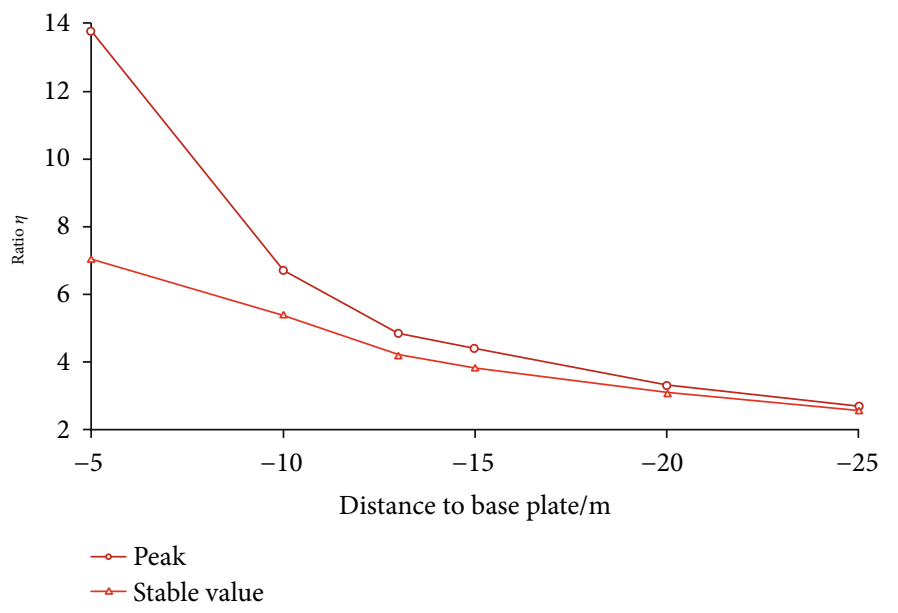

FIgURe 13: Peak and stable value of the ratio of two-way stress at different depths.

the coal wall, and $10 \mathrm{~m}$ to $40 \mathrm{~m}$ from the open cut and $10 \mathrm{~m}$ to the coal wall $30 \mathrm{~m}$ end symmetrical area.

4.3. Bidirectional Stress Distribution in Different Depths of Floor. As the FGER is arranged under the coal seam, the FGER is arranged at $13 \mathrm{~m}$ below the coal seam in the longitudinal layer of the rock layer, in order to deeply understand the bidirectional stress ratio distribution law at different depths of the coal seam floor, verify the rationality of the longitudinal selection position of the FGER, and extract the bidirectional stress ratio of different depths $(-5 \mathrm{~m},-10 \mathrm{~m},-13 \mathrm{~m}$, $-15 \mathrm{~m},-20 \mathrm{~m},-25 \mathrm{~m})$ under the coal seam at monitoring line 6 (as shown in Figure 12).

It can be seen from Figure 12 that the values and characteristics of bidirectional stress ratio in the projection range of the coal wall are basically the same. In the range of goaf projection, the results at all depths show M-shape characteristics, but the difference between the peak value and the value in peak valley is obvious. The peak values of bidirectional stress ratio at different depths under the coal seam floor correspond to $13.74,6.69,4.83,4.40,3.32$, and 2.68 , respectively. Under the coal seam floor, the stable values of bidirectional stress ratio in the middle of goaf with different depth are 7.02 , $5.40,4.21,3.83,3.09$, and 2.59 , respectively. Through the research on the peak value and stable value of bidirectional stress ratio at different depths (as shown in Figure 13), it can be concluded that the peak value and stable value of bidirectional stress ratio at the projection of goaf are reduced by 7.05 and 1.62 from - $5 \mathrm{~m}$ layer to - 10 m layer. From - $10 \mathrm{~m}$ layer to - $15 \mathrm{~m}$ layer, the peak value and stable value of bidirectional stress ratio at the projection of goaf decreased by 2.29 and 1.57; from - $15 \mathrm{~m}$ layer to - $20 \mathrm{~m}$ layer, the peak value and stable value of bidirectional stress ratio at the projection of goaf only reduced by 1.08 and 0.74 , and finally reached - $25 \mathrm{~m}$ layer, the decrease value of bidirectional stress ratio peak value and stable value at goaf projection was only 0.64 and 0.5 .

To sum up, the concentration degree of bidirectional stress ratio under the coal seam will also significantly decrease with the increase of distance to the coal seam floor. The closer the distance is to the coal seam, the greater the gap between the maximum value and the stable value. When the distance from the coal seam is less than $10 \mathrm{~m}$, the peak value and stable value of the bidirectional stress ratio decrease obviously with the increase of the distance to the floor. When the distance to the coal seam is more than $10 \mathrm{~m}$, the peak value and stable value of the bidirectional stress ratio will decrease with the increase of the distance to the floor and begin to show an approximate linear rule. Because the bidirectional stress ratio is large and changes violently within the distance of $10 \mathrm{~m}$ below the coal seam, it is not suitable to arrange floor roadway. When the FGER is arranged $13 \mathrm{~m}$ below the coal seam in the longitudinal layer of the rock, the extreme value and stable value of the bidirectional stress ratio in the projection range of the goaf of this layer are 4.83 and 4.21, respectively. If the FGER is arranged at the lower position of the longitudinal layer, the decrease of the bidirectional stress ratio environment will not be obvious, but it will be accompanied by the decrease of the thickness of the water resisting layer of the floor and the increase of the risk of water inrush. Therefore, combined with the layer selection factors of the longitudinal layout of the FGER and the environmental analysis of the bidirectional stress, the FGER is arranged at $13 \mathrm{~m}$ below the working face in the longitudinal layer, which can not only ensure no water inrush from the floor but also ensure the maximum gas drainage effect.

\section{Conclusion}

Through the numerical simulation of the floor stress distribution characteristics and the bidirectional stress ratio distribution law of the FGER in 11060 working face under the influence of mining, the following main conclusions are obtained:

(1) Based on the law of stress recovery in the goaf, the double-yield equivalent filling method was selected in the numerical simulation to fill the goaf, which better reflects the stress-strain relationship of the broken rock mass in the goaf under the action of the overlying rock 
(2) According to the characteristics of the stress state and the bidirectional stress ratio of each area, the stress state from the edge of the numerical model to the middle of the goaf can be divided into the following four types: the original rock stress ratio area, the boost pressure low-stress ratio area, the pressure relief low-stress ratio area, and the unloading compression high-stress ratio area

(3) The longitudinal layer of the FGER of the 11060 working face of the Zhaogu No. 2 coal mine should be located $13 \mathrm{~m}$ below the coal seam floor. This can ensure the maximum gas drainage effect while preventing water inrush from the floor

\section{Data Availability}

The data used to support the findings of this study are available from the corresponding author upon request.

\section{Conflicts of Interest}

The authors declare no conflict of interest.

\section{Acknowledgments}

This research has been supported by the National Natural Science Foundation of China (Grant No. 51774288) and the Fundamental Research Funds for the Central Universities (Grant No. 2020YJSNY10).

\section{References}

[1] Y. L. Zhao, Y. X. Wang, W. Wang, L. Tang, Q. Liu, and G. Cheng, "Modeling of rheological fracture behavior of rock cracks subjected to hydraulic pressure and far field stresses," Theoretical and Applied Fracture Mechanics, vol. 101, pp. 5966, 2019.

[2] Y. L. Zhao, L. Y. Zhang, J. Liao, W. J. Wang, Q. Liu, and L. Tang, "Experimental study of fracture toughness and subcritical crack growth of three rocks under different environments," International Journal of Geomechanics, vol. 20, no. 8, article 04020128, 2020.

[3] T. Zhang, X. He, Y. Liu, Y. Zhao, K. Yang, and X. Yu, "Experimental study on permeability response in fractured rock to the effect of hydro-mechanical coupling, fracture geometry, and component content," Natural Hazards, vol. 105, no. 2, pp. 1439-1451, 2021.

[4] Y. L. Zhao, L. Y. Zhang, W. J. Wang, Q. Liu, L. M. Tang, and G. Cheng, "Experimental study on shear behavior and a revised shear strength model for infilled rock joints," International Journal of Geomechanics, vol. 20, no. 9, article 04020141, 2020.

[5] Y. L. Zhao, C. S. Zhang, Y. X. Wang, and H. Lin, "Shear-related roughness classification and strength model of natural rock joint based on fuzzy comprehensive evaluation," International Journal of Rock Mechanics and Mining Sciences, vol. 137, article 104550, 2021.

[6] Y. Z. Li, T. Huang, B. L. Dai, and C. Cai, "Prediction model of localization deformation of rocks considering the third devia- toric stress invariant," Chinese Journal of Rock Mechanics and Engineering, vol. 29, no. 7, pp. 1450-1456, 2010.

[7] C. Thornton and L. Zhang, "On the evolution of stress and microstructure during general 3D deviatoric straining of granular media," Géotechnique, vol. 60, no. 5, pp. 333-341, 2010.

[8] Z. Y. Wang and H. Q. Liu, Coal Mining on Confined Aquifer, Coal Industry Press, Beijing, 1996.

[9] X. R. Zhai, J. W. Wu, H. M. Zhang, S. H. Shen, and N. C. Tian, "Study on water-inrush mechanism of mining floor of deep coal seam in mine shaft based on fluid-solid coupling," Coal Science \& Technology, vol. 45, no. 6, pp. 170-175, 2017.

[10] L. I. Liangjie, Y. Youquan, and Q. Minggao, "Research on the tests of water-inrush from floor simulated by similar materials," Coal Geology and Exploration, vol. 25, 1997.

[11] B. Y. Li, "The "lower three zones" theory of preventing water inrush from mine floor and its development and application," Journal of Shandong Institute of Mining and Technology, vol. 18, no. 4, pp. 4-7, 1999.

[12] L. Q. Shi and J. Han, "Theory and practice of "four zones" division in mining coal seam floor," Journal of China University of Mining and Technology, vol. 34, no. 1, pp. 16-23, 2005.

[13] Y. F. Gao, L. Q. Shi, H. J. Lou, and X. L. Niu, Law of Water Inrush from Floor and Dominant Surface of Water Inrush, China University of mining and Technology Press, Xuzhou, 1999.

[14] A. J. Shao, J. P. Peng, and T. S. Liu, "Research on a cusp catastrophic model of water bursting in pit floors," Chinese Journal of Geotechnical Engineering, vol. 23, no. 1, pp. 38-41, 2001.

[15] J. M. Wang, "Simulation and observation of the mechanism of confined water advancing along the coal seam floor and leading to water inrush," Chinese Journal of Geotechnical Engineering, vol. 21, no. 5, pp. 546-549, 1999.

[16] X. R. Meng, C. H. Xu, Z. N. Gao, and X. Q. Wang, "Stress distribution and damage mechanism of mining floor," Journal of China Coal Society, vol. 35, no. 11, pp. 1832-1836, 2010.

[17] S. L. Lu, J. Y. D. Jiang, and Y. L. Sun, "Selection of offset Z between roadway and upper coal seam," Journal of China University of Mining \& Technology, vol. 1, no. 1, pp. 4-10, 1993.

[18] S. L. Lu, Y. L. Sun, and Y. D. Jiang, "Selection of the horizontal distance $\mathrm{X}$ between the roadway and the upper coal pillar edge," Journal of China University of Mining \& Technology, vol. 1, no. 2, pp. 4-10, 1993.

[19] H. L. Zhang, Study on Stress Transmission Laws of Mining Floor and Its Influence on Stability of Floor Roadway, [Ph.D. thesis], China University of Mining \& Technology, Beijing, 2011.

[20] L. G. Wang, M. Han, Z. S. Wang, and S. B. Ou, "Stress distribution and damage law of mining floor," Journal of Mining \& Safety Engineering, vol. 30, no. 3, pp. 317-322, 2013.

[21] Y. E. Li, Surrounding Rock's Failure Characteristic and Rational Location of Floor Gas Drainaging Roadway above the Deep Confined Water, [Ph.D. thesis], China University of Mining \& Technology, Beijing, 2018.

[22] Q. B. Meng, L. J. Han, W. G. Qiao, D. G. Lin, S. Y. Wen, and J. Zhang, "Deformation failure characteristics and mechanism analysis of muddy weakly cemented soft rock roadway," Journal of Mining \& Safety Engineering, vol. 33, no. 6, pp. 10141022, 2016.

[23] W. J. Yu, W. J. Wang, W. Z. Huang, and H. Wu, "Deformation and failure mechanism of high-stress soft rock roadway and 
repair control technology," Journal of China Coal Society, vol. 39, no. 4, pp. 614-623, 2014.

[24] S. W. Liu, W. G. Zhang, Y. Y. Gan, and S. J. Dong, "Feature and control of failure and movement of floor rock mass in deep mine roadway," Journal of Henan Polytechnic University (Nature Science), vol. 31, no. 1, pp. 30-34+38, 2013.

[25] Z. Q. Zhao, Mechanism of Surrounding Rock Deformation and Failure and Control Method Research in Large Deformation Mining Roadway, China University of Mining \& Technology, Beijing, 2014.

[26] N. J. Ma, J. Li, and Z. Q. Zhao, "Distribution of the deviatoric stress field and plastic zone in circular roadway surrounding rock," Journal of China University of Mining \& Technology, vol. 44, no. 2, pp. 206-213, 2015.

[27] W. J. Wang, G. Y. Guo, Y. J. Zhu, and W. J. Yu, “Malignant development process of plastic zone and control technology of high stress and soft rock roadway," Journal of China Coal Society, vol. 40, no. 12, pp. 2747-2754, 2015.

[28] N. J. Ma, X. D. Zhao, Z. Q. Zhao, J. Li, and X. F. Guo, "Stability analysis and control technology of mine roadway roof in deep mining," Journal of China Coal Society, vol. 40, no. 10, pp. 2287-2295, 2015.

[29] W. J. Wang, E. Y. Dong, and C. Yuan, "Boundary equation of plastic zone of circular roadway in non-axisymmetric stress and its application," Journal of China Coal Society, vol. 44, no. 1, pp. 105-114, 2019.

[30] X. F. Guo, L. F. Guo, N. J. Ma, Z. Q. Zhao, and C. Li, “Applicability analysis of the roadway butterfly failure theory," Journal of China University of Mining \& Technology, vol. 49, no. 4, pp. 646-653+660, 2020.

[31] C. Li, T. H. Huo, Z. Wu, K. Lv, and B. Zhang, "Mechanism and stability control of uneven severe roof deformation of dynamic pressure roadway," Journal of Central South University (Natural Science Edition), vol. 51, no. 5, pp. 1317-1327, 2020.

[32] M. G. Qian, P. W. Shi, and J. L. Xu, Mine Pressure and Rock Formation Control, China University of Mining and Technology Press, Xuzhou, 2010.

[33] H. Yavuz, "An estimation method for cover pressure reestablishment distance and pressure distribution in the goaf of longwall coal mines," International Journal of Rock Mechanics and Mining Sciences, vol. 41, no. 2, pp. 193-205, 2004.

[34] M. Bai, F. Kendorski, and D. Van Roosendaal, "Chinese and North American high-extraction underground coal mining strata behavior and water protection experience and guidelines," in Proceedings of the 14th International Conference on Ground Control in Mining, West Virginia University, Morgantown, WV, USA, 1995.

[35] M. Salamon, "Mechanism of caving in longwall coal mining," in Rock mechanics contributions and challenges: Proceedings of the 31st US Symposium, pp. 161-168, Golden, Colorado, 1990. 